\title{
Гендерный аспект экологии человека в романе Дмитрия Липскерова «О нем и о бабочках»
}

\author{
Инна Калита (Ústí nad Labem)
}

\begin{abstract}
Аннотация
Статья представляет роман Дмитрия Липскерова «О нем и о бабочках» (2016) в общем контексте романной прозы писателя. Рассматривается новая для автора тема гендерных изменений в современном обществе. Завязка романа основана на реминисцентной связи с «Носом» Н. В. Гоголя - главный герой обнаруживает отсутствие своего мужского органа. Д. Липскеров творчески осмысливает гендерные сдвиги. Эти изменения перекликаются с проблематикой, отраженной К. Чапеком в «Россумских универсальных роботах» (1920). Авторы разных культур и поколений показывают, что процессы «роботизации» и «феминизации» человеческого общества ведут к его вырождению. «Вымывание» из взаимоотношений мужчины и женщины чувств и веры является причиной духовного оскудения и нарушает экологию человеческого существования.
\end{abstract}

\section{Ключевые слова}

современный русский роман; магический реализм; реминисценции; гендерные сдвиги; Дмитрий Липскеров; тематическая инновация; экология человека

\section{Abstract \\ Gender Aspect of Human Ecology in Dmitry Lipskerov's Novel About Him and About Butterflies}

The article presents Dmitri Lipskerov's novel About Him and About Butterflies (2016) in the general context of the writer's novel prose. The author deals with a new topic of gender change in the modern society. The plot of the novel is based on reminiscence connection with N. Gogol's Nose, since Lipskerov's main character discovers the absence of his male organ. D. Lipskerov interprets gender changes creatively. These changes resonate with the problems described by K. Capek in Rossum's Universal Robots (1920). The authors from different cultures and generations show that the processes of "robotization" and "feminization" of human society lead to its degeneration. Disappearing of feelings and faith in a relationship between a man and a woman causes spiritual impoverishment and violates the ecology of human existence.

\section{Key words}

modern Russian novel; magical realism; reminiscences; gender changes; Dmitri Lipskerov; thematic innovation; human ecology 


\section{Введение}

«нига - это ежесекундное учение, открытие
в заученнъхх десятилетиями строках
все нового и нового в вашей душе...»

Д. Липскеров

Дмитрий Липскеров - яркая личность современной литературной сцены России. Благодаря своим произведениям, наполненным превращениями, нетрадиционной структуре образов и разветвлениям сюжета на несколько параллельных линий и пространств, в которых герои могут пребывать попеременно, писатель снискал титул магического реалиста. Реминисценции и магические связи, объединяющие две естественные для творчества Липскерова плоскости - реалистическую и магическую, представлены в книге «Магические реминисиениии в творчестве Дмитрия Липскерова» ${ }^{1}$.

Цель данной статьи - проанализировать новый роман Д. Липскерова « $O$ нем и о бабочках» (2016) с точки зрения тематической инновации, исходя из общего контекста творчества писателя.

«О нем и о бабочках» - чрезвычайно многоплановый роман, заслуживающий подробного анализа. При его рассмотрении необходимо сравнение с гоголевским «Носом». Говорить о такой параллели позволяют и предыдущие романы писателя. Новый роман «O нем и о бабочках» подтверждает творческое «родство» и представляет созвучные гоголевскому методу приемы, эстетические и экспрессивные параллели. Однако объем статьи не позволяет произвести всесторонний анализ данного романа. Поэтому мы затронем лишь один аспект - новую для автора тему гендерных изменений в современном обществе, т.е. его творческое осмысление изменения социальных норм и стереотипов, определяющих «стандартные» роли и виды поведения, характерные для женщин и мужчин.

\section{1. Общая характеристика романной прозы Дмитрия Липскерова: основной метод, жанровая специфика, эстетические принципы}

Главным методом Д. Липскерова с самого начала его творчества является магический реализм. Этот термин и понятие вызывает много споров и на сегодняшний день относится к категории терминов, находящихся в поле научных дискуссий, одновременно относится к модным словам, которыми часто пользуются журналисты.

Мы исходим из следующего определения термина магический реализм:

1 KALITA, Inna: Magičeskije reminiscencii v tvorčestve Dmitrija Lipskerova. Moskva: Diksi Press, 2015. 
«Магический реализм - индивидуальный метод, не привязанный ко времени, в его основе в разной степени представлены место + маргинальность + мифология. Магический реализм - не массовое явление, а инструмент конкретного мастера.

В основе произведений, созданных методом магического реализма, лежат два слагаемых - реальная и «зазеркальная» плоскости, оббединеннъе невидимыми «воротами»- многоканальным, межкультурньм, сквозьвременньм переходом. Канва магического реализма - реальная (видимая глазу) жизнь, переплетенная с «зазеркальем» (разными формами работь подсознания). Переход между реальностью и «зазеркальем»- сон / смерть / жизнесмертие (тоннель для путешествия души). Магический реализм - один из методов, развивающихся в русле самого распространенного литературного направления - реализма» ${ }^{2}$.

Магический реализм, как особый, и довольно редко встречающийся литературный метод, приобретает особые черты не только в отдельных национальных традициях (сильнейшей считается латиноамериканская), но в разных пропорциях он проявляется и в творчестве отдельного писателя - магического реалиста.

М. Н. Панчехина считает магический реализм вполне утвердившимся методом, в котором «автор специфически использует категорию времени с иелью раскрытия субъективности и относительности данной категории»; “художественное пространство является магическим и не совпадает с каким-либо реальным географическим и историческим пространством» ${ }^{3}$, а историческое и теоретическое осмысление метода «не сводится к единственной культуре и не замъкается на конкретной начиональной традииии» 4 .

В развитии своего творческого метода Д. Липскеров прошел два основных этапа: первый - драматургический (1988-1993: в то время самым популярным было сравнение его с Чеховым). Первые пьесы не были ученическими, они сразу же были поставлены в театре. Второй этап - романный (с 1996 года: в самом начале возникло сравнение Липскерова с Маркесом, далее последовало множество других). Первый роман свидетельствовал о зрелости автора, поэтому говорить о поисках пути и значительной эволюции писателя не приходится. Трансформации в его творчестве заметны в таких параметрах, как (1) смена главного героя, (2) изменение пропорций магического и реального плана, (3) расширение рамок полифонического романа (максимализация эмоций и внутреннего Я - обращение к жанру гептамерона; (4) усиление роли социального контекста и социальной сатиры; (5) углубление в религиозно-этические размышления.

В каждом романе автора пропорции реального и магического индивидуальны, они неравномерны в силу максимализации или минимизации роли «социального интерьера». Магическая плоскость более ощутима, выпукла и красочна в его первых романах, в частности, в «Сорок лет Чанчжоэ» (1996). Позднее, не отходя от основного метода, в роман «Демоны в раю» (2008) Липскеров вписывает сильную

2 Ibidem, s. 219-220.

3 PANČECHINA, M. N.: Magičeskij realizm i problema vizual'nogo v chudožestvennom proizvedenii: postanovka voprosa (na materiale romana M. Bulgakova "Master i Margarita”). In: Mova i kul'tura, 2011. V. 14, t. 7, s. 288-294, 291.

4 PANČECHINA, M. N.: «Čudesnaja real'nost'» $i$ struktura prostranstva v kontekste magičeskogo realizma. In: Literaturovedčeskij sbornik. V. 53-54: Aktual'nye problemy filologii. Doneck: DonNU, 2015, s. 65-71. 
социальную ноту. Гептамерон «Мясо снегиря» (2009) для поклонников писателя был неожиданностью. Многие критики и читатели не согласились с определением автора и не восприняли данное произведение как роман. Традиционная для Липскерова магия «улетучилась», на первое место вышли волнения оголенной души. Две основные плоскости - реалистическая и магическая уступили в этом произведении место эмоциям - глубокому чувствованию. В «Мясе снегиря» не так важен «интерьер», и не так важно соблюдение полагающегося для жанра гептамерон условия - собрание новелл. Объединенные в гептамероне тексты скорее можно отнести к эссе, а то одновременно по нескольким параметрам: (1) по структуре малого жанра, (2) по личной предистории, (3) по чрезвычайной открытости автора перед читателем.

Эссе, по мнению В. Акудовича, это остров, на который можно попасть только после караблекрушения, поэтому эссе всегда начинается с безутешного одиночества. По В. Акудовичу: эссе - мужественный жанр. В рассказе автор раздевает героя на людях - в эссе он раздевается сам 5 . Именно так поступает Липскеров в «Мясе снегиря». Используя категории Ю. Лотмана, можно сказать, что писатель увеличивает внутреннюю семиотическую неоднородность текста, развивая в нем структурно-контрастные подтексты, имеющие тенденцию к все большей автономии.

«Колебание в поле «семиотическая однородность <-> семиотическая неоднородность» составляет одну из образующих историко-литературной эволючии. Из других важньх ее моментов следует подчеркнуть напряжение между тендениией к интеграчии - преврашению контекста в текст (складываются такие тексты, как «лирический чикл», «творчество всей жизни как одно произведение» и т. п.) и дезинтеграчии - превращению текста в контекст (роман распадается на новеллы, иасти становятся самостоятельными эстетическими еди ницами). В этом прочессе позиции читателя и автора могут не совпадать: там, где автор видит иелостный единый текст, иитатель может усматривать собрание новелл и романов...» ${ }^{6}$

«Мясо снегиря» - своебразный переход и одновременно пролог к более глубокому познанию себя самого. Отразившийся в гептамероне кризис среднего возраста разрастается и гиперболизируется в следующем романе автора. Потерю веры и поиски новых ориентиров запечатлевает писатель в романе «Всякий капитан - примадонна» $(2011)^{7}$. Книга пронизана бескрайним, непреодолимым холодом - мужским одиночеством. Оно определяет смену главного образа. Женщина, всегда занимавшая у Липскерова главное место, уступает первенство мужчине. Все тускнеет на фоне неизлечимого мужского одиночества, всеобъемлющей безысходности, исчезновения жизненных целей. Исследование внутреннего и внешнего пространства усиливается развитием архетипичной связи отец - сын, и подчеркивается взросле-

5 AKUDOVIČ, Valjancin: Ese pra ese. In: Dyjalohi z Boham: supljot intelihibel'nyh refljeksij. Minsk: Lohvinay̆, 2006, s. 86-90.

6 LOTMAN, Ju. M.: Semiotika kul'tury i ponjatie teksta. In: Lotman Ju. M. Izbrannye stat'i. T. 1. Tallinn, 1992, s. $129-132$.

7 Данный роман рассмотрен в сравнении с романом современного чешского писателя Павла Брича в статье: KALITA, I. V.: Mežkulturnyj dialog sovremennikov: Dmitrij Lipskerov vs. Pavel Brycz. In: (red. KAPRUSOVA, M. N., TOLOKONNIKOVA, S. Ju.) Poetika chudožestvennogo teksta. Borisoglebsk: OOO «Kristina i K», 2015, s. 5-13. 
нием и слиянием сына с отцом как мужским архетипом. Женский архетип и его связи уходят на задний план и, образуя лишь фон, уступают место архетипу мужчины. Архетип мужчины более значим и в романе «Теоря описавшегося мальчика» (2013).

Роман «O нем и о бабочках» открывает следующую перспективу в реализации женского и мужского архетипов - в нем находят отражение современные гендерные изменения. Символически вписывая в книгу общемировые тенденции гендерных сдвигов последних десятилетий, автор ставит острый вопрос экологии существования человека, гармонии двух неразрывно связанных частей единого целого - женщины и мужчины.

\section{2. «О нем и о бабочках»}

\section{1 Завязка как тематическая перекодировка известного приема}

В романе «О нем и о бабочках» Д. Липскеров не изменяет своему основному методу, в произведении присутствует плоскость реальная и события, кажущиеся нереальными. Завязка романа основана на моменте, когда главный герой, мужчина пятидесяти с лишком лет, обнаруживает отсутствие своего мужского органа. Первая возникающая реминисцентная связь - гоголевский «Нос». И в данном примере видимо следует говорить не только о приеме художественном - исчезновение органа как прием привлечения внимания к определенной проблеме, но и о возникновении символической актуализирующей функции, выполняемой определенным органом человеческого тела.

Главный герой романа Д. Липскерова «О нем и о бабочках» - Арсений Андреевич Иратов. Роман начинается его описанием. Усомнившись в правильности долгого приема медицинских препаратов, Иратов решает поменять терапию - таблетки, принимаемые им на протяжении долгого времени. Новые дорогостоящие пилюли, выписанные знакомым врачем, облегчения не приносят.

"[...] до этого неизменное давление скакало, [...], а стул оставлял желать куда лучшего. Но самыми неприятными оказались приходы состояния дежавю, длямиеся не редкие мгновения, как у обычных людей, доставляя им радостное удивление, а мучительные часы гиперреализма, унося сознание Иратова в прошлое, заставляя переживать ушедшие времена до полной истерзанности, хотя его жизнь было трудно сравнить с жизнъю библейских страдальиев: вполне себе человеческая, со взлетами и падениями. ${ }^{8}$

Когда Иратов находился в этом тревожном состоянии, ему позвонил из Израиля партнер по старому, почти погибшему бизнесу по перепродаже сапфиров. Выслушав историю недуга, он был немногословен: «счастье, если человек нашел свою таблетку [...] Большинство не находят своей таблетки, не находят!!! А вам Господъ ее открыл!» Это заставило Иратова задуматься и вернуться к старой терапии. Уже на следующий день он был полон энергии.

8 LIPSKEROV, Dmitrij: O nem i o babočkach. Moskva: AST, Redakcija Jeleny Šubinoj, 2016, s. 4. 
Описанное состояние при изменении терапии (отказ от старой терапии - новые таблетки - возврат) сравнимо с популярным приемом сна, снимающим с автора и его героя «ответственность» за происходящее, а само происходящее переносится в разряд «возможного», не обязательно реального действия.

Значимым в романе является образ Верочки, молодой женщины тридцати лет, гражданской жены Иратова, с которой они живут душа в душу... «Верочка проживала этажом выше, куда ее заселил Арсений Андреевич, объяснив это необходимостью проводить большую часть в одиночестве и покое, да и полной невозможностью заснуть с женщиной в одной постели [...].»9

Верочка, не смотря на разницу в возрасте, искренне любит Иратова и мечтает о ребенке. Она тайно ходит в церковь и решается попросить поддержки высших сил в этом вопросе. Очередь к иконе святой Матроны оказывается слишком большой и, простояв четыре часа, Верочка хочет уйти, т.к. боится опоздать на ужин с Иратовым. В этот момент впервые появляется загадочный герой - связующая нить времен и культур, таинственная тень и образ, который неоднократно будет появляться в книге в разных важных ситуациях.

«[...] здесь Верочку взял под локоть какой-то, взлохмаченный, с горбатьмм носом старик, похожий на грека, очень худой и хмурый личом, в черном до пят пальто, и, прочедив, что у него занято местечко впереди, возле самого входа, потянул ее за собой. Она не успела и рта раскрытъ, как оказалась возле украшенной иветами иконъ Матронъ. [...] И она стала просить Матрону о чуде, о маленьком мальчике с черными глазами [...].»10

Необходимо отметить, что имя героини выбрано автором не случайно. Кроме того, что у Липскерова на протяжении всего его творчества наблюдается обращение к «говорящим» именам, Верой он символически именует не только женщину. В романе «Теория описавшегося мальиика» так неоднократно называет себя человек-ксилофон. Это образ, «стабилизирующий» общество, заставляющий задуматься о роли человека и смысле его существования. Верочка в романе «O нем и о бабочках» - образ не лишенный человеческих грехов, она подвержена искушениям. Однако ангел, делая попытку уговорить ее неугомонного искусителя, особо произносит фразу: «Она - Верушшшка!....». И в Веру - человека-ксилофона, и в Верушку - героиню романа «O нем и о бабочках» автор вкладывает более глубокий смысл. Это имя - символ веры, котрая не должна покинуть человека.

\section{2 Самостоятельная жизнь органа - человек как «половина монеты»}

Пропавший орган Иратова начинает самостоятельную жизнь в человеческом обличии и, прибыв в Москву, назначает встречу своему «хозяину». Тот вынужден познакомить его с Верочкой, и представляет Эжена (имя человека - органа) как своего сына. Эжен сооблазняет Верочку. Далее события набирают стремительный ход.

9 Ibidem, s. 3.

10 Ibidem, s. 9-10. 
Иратов, смирившийся с мыслью об операции по фаллопластике, приходит к своему врачу. Тот сообщает ему, что с ним случилось то же, и демонстрирует свой практически женский лобок, добавляя, что за последние два дня у него было двенадцать таких пациентов. Невиданная до этого «эпидемия» исчезновения мужских органов расширяется, а Эжен продолжает связь с Верочкой.

Вскоре «с сенсаиионным заявлением выступила Всемирная андрологическая организаиия, имеющая итаб-квартиру в Нъю-Йорке, заявившая, что по их данным восемьдесят проұентов мужчин, а также подростков, мальчиков и даже младениев в течение одного месяиа лишились своих детородных органов. ${ }^{11}$

«- Проверены все мужские особи на планете! - подтвердил директор NASA. - И пигмеи в том числе.

-И ни укого не... Что, у всех?...

- Абсолютно.

- А у животных?

- Плодятся и размножаются!» ${ }^{12}$

СМИ констатировали, что человечеству осталось жить не более ста двадцати лет, т.к. появляющиеся на свет мальчики рождаются без детородных органов и очень похожи на девочек.

Д. Липскеров отмечает существующую разницу восприятия гендерных ролей на Западе и в России. Автор «ментально насыщает» художественный текст, используя прием контраста, указывая на традиционное восприятие роли женщины в России. Исходя из этого он преподносит разные «итоги» гендерных сдвигов: на Западе противостояние наблюдалось между женскими лидерами и лидерами мировых религий, настаивавших на переходе власти к церкви к непорочным мужчинам. В ответ женщины высмеивали педофильство религиозных деятелей.

«Спокойнее дело обстояло в странах третъего мира и в России. Здесь женшины не так буйствовали, кроме лесбийских группировок, исторически не желая управлять государством, выбирал роль кухарки, а не президента. Россиянки были довольны уже тем, ито теперь мужик приходил домой вовремя, утерял желание играть в домино и смотреть вялый гомосексуальный футбол. Пусть нет секса, он и до этого случался так себе, но муж и балет при ней!

Мужчины мира потеряли тестостерон. Кровъ была водой, а мозг - наростом жира. Все мужское население Европы просиживало большую часть времени в кинотеатрах, поедая тоннами попкорн и удивляясь такой страстности мужчин на экранах. Зачем иеловать иъю-то грудь, хватать кого-то за заднии?? И негигиенично и неинтересно. Порноиндустрия развалилась в считаные месящы, работая лишь на лесбийский рынок.» ${ }^{13}$

Конец книги, описывающий феминизацию мужского населения планеты предлагает реминисцентные связи с пьесой (по определению автора -

\footnotetext{
11 Ibidem, s. 202-203.

12 Ibidem, s. 223.

13 Ibidem, s. 224.
} 
коллективная драма) К. Чапека «Россумовские универсальные роботъ» (RUR, 1920), в которой роботы захватывают власть над человеком. В результате наступает катастрофическая ситуация - они не умеют самовоспроизводится и потому необходимо вернуть человека.

«Книги ничего уже не говорят! Они немъ - как и все вокруг. Умерли, умерли вместе слюдъми! И не ищи! [...] Спать, видеть сны, видеть людей... Как, звезды еще существуют? К чему звезды, если нет людей? [...] Освежи, освежи мне голову, древняя ночъ! Божественная, дивная, какой ты бывала встарь [...] Нет влюбленных, нет снов. [...] мертв сон без сновидений; и ты не освятишь уже ничьих молитв; не благословишь, о мать, сердеи, трепемуших от любви.» ${ }^{14}$

Липскеров обращает внимание на то, что Человек - это две неразрывно связанные половинки - мужиина без жены - как половина монеты! Не имеет цены!

Он рисует картину, в которой мужчина как представитель одного из полов исчезает. «В мире восторжествовал унисекс и возродился средневековый балаган, в котором жирные тетки и бывшие дядъки показывали сиенки из прошлой жизни, заставляя зрителей гоготать над попытками героев совокупиться.» ${ }^{15}$

Созданная автором картина впечатляет: баритоны и басы уходят в небытие, растолстевшие балеруны не могут танцевать, искусство вырождается, исчезает мужской спорт. Нуждаясь в эндорфинах, люди начинают больше пить и есть.

\section{Заключение}

Роман Д. Липскерова «О нем и о бабочках» многопланов и тематически разнообразен. Он представляет разные временные модусы - воспоминания, описания значимых отрезков жизни Иратова, большой «крен» в сложную и опасную атмосферу 90-ых, а также «поворот» в совершенно отличающуюся от городской жизни деревенскую атмосферу; присутствие образа Антипатроса - связующей нити времен и пространств - все это «расщепляет» романное время. «Расщепление» и «переплавка» времени и пространства - один из основных, наиболее ярких приемов Д. Липскерова, которым он неизменно пользуется в каждом своем произведении.

Роман стилистически «углубляет» шкалу между низким и высоким. С одной стороны, автор обращается к «низкому»: во-первых, говорит об исчезновении «мужского достоинства» - называет орган, о котором в общем в русской культурной традиции принято выражаться либо нецензурно в определенном контексте и окружении, либо иносказательно, намеком. Во-вторых, «низкое» очень активно и в плане лексическом, автор использует сленг и инвективы. Таким образом он насыщает текст отрицательно маркированным тематическим и лексическим материалом.

14 ČAPEK, Karel: Rossumskie universal'nyje roboty. In: Elektronnaja biblioteka Royallib.ru. URL: http://royallib.com/book/chapek_karel/RUR.html

15 LIPSKEROV, Dmitrij: O nem i o babočkach. Moskva: AST, Redakcija Jeleny Šubinoj, 2016, s. 226. 
С другой стороны присутствует «уравновешивающая» тенденция. Особенно последняя треть текста романа насыщена философскими идеями, вопросами религиозного познания, высокими нотами.

В данной статье представлено лишь одно тематическое направление, являющееся в творчестве автора инновацией. Затронутая тема гендерных изменений в современном обществе перекликается с темой, сформулированной К. Чапеком в «Россумских универсальных роботах». Несмотря на то, что пьесу Чарека и роман Д. Липскерова разделяет почти сто лет, оба произведения звучат как предупреждение человечеству. Названные проблемы - «роботизация» и «феминизация» человеческого общества ведут к его вырождению. Уходящие из взаимоотношений мужчины и женщины вера и чувства - признак духовной деформации, нарушающей экологию человеческого существования.

Рассмотренную тему Д. Липскеров не рисует трагедийными красками и не использует назидательные ноты. Его сатира, которую с полным правом можно назвать острой, в сравнении с решением подобной темы Ф. Кафкой, не звучит «испепеляюще». Роман «О нем и о бабочках», как и все произведения нашего современника, оставляет человеку возможность перехода в другое измерение, веру и возможность выбора.

\section{Библиография}

AKUDOVIČ, Valjancin: Ese pra ese. In: Dyjalohi z Boham: supljot intelihibel'nyh refljeksij.

Minsk: Lohvinay̆, 2006. s. 86-90.

KALITA, Inna: Magičeskije reminiscencii v tvorčestve Dmitrija Lipskerova. Moskva: Diksi Press, 2015.

ČAPEK, Karel: Rossumskie universal'nyje roboty. In: Elektronnaja biblioteka Royallib.ru. URL: http: / / royallib.com/book/chapek_karel/RUR.html

LIPSKEROV, Dmitrij: O nem i o babočkach. Moskva: AST, Redakcija Jeleny Šubinoj, 2016.

LOTMAN, Ju. M.: Semiotika kul'tury i ponjatie teksta. In: LOTMAN, Ju. M.: Izbrannye stat'i. T. 1. Tallinn: Aleksandra, 1992, s. 129-132.

PANČECHINA, M. N.: Magičeskij realizm i problema vizual'nogo v chudožestvennom proizvedenii: postanovka voprosa (na materiale romana M. Bulgakova „Master i Margarita“). In: Mova i kul'tura, 2011. V. 14, t. 7, s. 288-294.

PANČECHINA, M. N.: «Čudesnaja real'nost'» $i$ struktura prostranstva v kontekste magičeskogo realizma.

In: Literaturovedčeskij sbornik. V. 53-54: Aktual'nye problemy filologii. Doneck: DonNU, 2015, s. $65-71$.

\section{PhDr. Inna Kalita, Ph.D.}

Katedra bohemistiky

Pedagogická fakulta, Univerzita Jana Evangelisty Purkyně v Ústí nad Labem

České mládeže 8, 40096 Ústí nad Labem, Česká republika

inna.kalita@ujep.cz 
